\title{
AMPliação das atividades das equipes NASF-AB EM SAÚdE MENTAL
}

\author{
Expansion of NASF-AB team activities on Mental \\ Health
}

\author{
Rosana Schiffer Cury ${ }^{1}$, Giseli Cipriano Rodacoski ${ }^{2}$, Christiane Luiza Santos ${ }^{3}$
}

1 Psicóloga, membro da equipe NASF-AB na Secretaria Municipal de Saúde de Tibagi - Paraná. ORCID: https://orcid.org/0000-0002-6743-2823

2 Psicóloga na PUCPR: SEAP - Serviço de Apoio Psicopedagógico; Docente na Escola de Saúde Pública do Paraná. Curitiba-PR. Mestre em Educação, Doutora em Biotecnologia - linha de pesquisa: Ensino na Saúde. ORCID: https://orcid.org/0000-0003-4837-9331

3 Cirurgiã-dentista, Professora Faculdades Pequeno Príncipe e Escola de Saúde Pública do Paraná Curitiba - PR. ORCID: https://orcid.org/0000-0002-8299-455X

CONTATO: Rosana Schiffer Cury | Rua Coronel Telêmaco Borba, 1186 | Casa 05 | Tibagi | PR | CEP: 84300-000 | Telefone: (42) 99155-2430 | Email: rosana.floraisdebach@gmail.com

COMO CITAR Cury RS, Rodacoski GC, Santos CL. Ampliação das atividades das equipes NASF-AB em saúde mental. R. Saúde Públ. 2019 Jul.;2(Suppl 2): 76-91

c) (i) Internacional. É permitida a reprodução parcial ou total desta obra, desde que citada a fonte.

RESUMO Este artigo apresenta o relato de experiência com a elaboração de um projeto de intervenção a ser aplicado no território de atuação profissional da autora, aluna do Curso de Especialização em Saúde Mental entre os anos de 2017 e 2018. A situação problema priorizada foi o processo de trabalho da equipe NASF-AB especialmente para atenção à Saúde Mental. Com base na possibilidade de atuação do NASF-AB descrita nos textos técnicos e teóricos foram identificadas lacunas de competências que determinaram propostas de ações. Foi utilizada a 
ferramenta 5W2H para descrever a metodologia do projeto de intervenção que pretende alcançar os objetivos por meio de inovações no processo de trabalho, desenvolvendo novos conhecimentos, habilidades e atitudes sobre práticas e saberes de núcleo e de campo em saúde mental.

PALAVRAS-CHAVE: Saúde Mental; Atenção Primária à Saúde; Trabalho; Equipes.

ABSTRACT This article presents the experience report with the elaboration of an intervention project to be applied in the area of professional activity of the author, a student of the Specialization Course in Mental Health between the years 2017 and 2018. The priority problem was the process of work of the NASF-AB team especially aimed at the attention to Mental Health. Based on the NASF-AB's ability to perform described in the technical and theoretical texts, competency gaps determining action proposals were identified. The $5 \mathrm{~W} 2 \mathrm{H}$ tool was used to describe the methodology of the intervention project aiming to achieve the objectives through innovations in the work process, developing new knowledge, skills and attitudes about core and field mental health practices and knowledge.

KEYWORDS: Mental Health. Primary Health Care. Health Quality Management.

\section{INTRODUÇÃO}

$\mathbf{N}$

o Brasil, o processo de elaboração da Política Nacional de Saúde Mental teve seu marco com a promulgação da Lei 10.216 em 2001 que dispõe sobre a proteção e os direitos das pessoas portadoras de transtornos mentais e redireciona o modelo assistencial em saúde mental'. No ano de 2011 a Portaria MS/GM n 3.088 institui a Rede de Atenção Psicossocial para pessoas com sofrimento ou transtorno mental e com necessidades decorrentes do uso do crack, álcool e outras drogas, no âmbito do Sistema Único de Saúde².

Os textos publicados atribuíam à Atenção Primária a coordenação do cuidado das condições crônicas e como política indutora, em janeiro de
2008, a Portaria 154 instituiu o Núcleo de Apoio à Saúde da Família (NASF) ${ }^{3}$ e, posteriormente, as Portarias Nacionais que Regulamentam a Atenção Básica - PNAB ${ }^{4: 5}$ regulamentaram o trabalho no NASF, que atualmente é apresentado como:

\footnotetext{
Constitui uma equipe multiprofissional e interdisciplinar composta por categorias de profissionais da saúde, complementar às equipes que atuam na Atenção Básica. É formada por diferentes ocupações (profissões e especialidades) da área da saúde, atuando de maneira integrada para dar suporte (clínico, sanitário e pedagógico) aos profissionais das equipes de Saúde da Família (eSF) e de Atenção Básica (eAB) $)^{5}$.
} 
A atual PNAB $^{5}$ estabeleceu a revisão de diretrizes para a organização da Atenção Básica, no âmbito do Sistema Único de Saúde (SUS), e nesta oportunidade o NASF sofre alteração em sua nomenclatura para: Núcleo Ampliado de Saúde da Família e Atenção Básica - NASF-AB, para fazer referência não mais a uma equipe de apoio, atendendo por solicitação, para se referir a um grupo de profissionais que integra a mesma equipe da unidade de saúde em uma modalidade ampliada e atende todos os usuários da área de abrangência da Unidade de Saúde, e não apenas os vinculados às equipes de Estratégia de Saúde da Família (ESF).

A proposta deste Projeto de Intervenção é problematizar a situação de uma equipe NASF-AB a partir das possibilidades de atuação apontadas pela literatura, para então identificar desafios e competências a serem desenvolvidas nas equipes e nos processos de trabalhos de modo a ampliar a capacidade de resposta do NASF-AB para o fortalecimento da Atenção Primária, especialmente no que se refere às necessidades de atenção à saúde mental no território da Unidade de Saúde.

Com a participação da psicóloga, autora deste projeto, no Curso de Especialização em Saúde Mental oferecido pela Escola de Saúde Pública, nos eventos promovidos pela SESA para o fortalecimento da Atenção Primária, e também pelo interesse em buscar maior assertividade nas ações de saúde, foi possivel identificar diversas lacunas de competência que precisavam ser desenvolvidas para melhor atuação do NASFAB.

O problema priorizado foi a falta de clareza entre os profissionais do NASF-AB sobre suas atribuições, que por meio deste projeto a autora espera superar.

\section{DIAGNÓSTICO SITUACIONAL}

O município cenário deste estudo possui 19.344 habitantes $^{6}$ dos quais 11.668 residem na área urbana e 7.676 na área rural, com densidade demográfica de 6,55 habitantes $/ \mathrm{km}^{2}$. A agroindústria é a principal atividade produtiva (37\%), seguida por comércio e a reparação de veículos (10\%). A renda média domiciliar per capita7 é de R\$ 535,27.

A estrutura de saúde existente no Município em 2018, ano em que foi concluído este projeto, estava assim apresentada: Atenção primária: 05 Unidades Básicas de Saúde (UBS) e 06 equipes de Estratégia de Saúde da Família (ESF) com atendimento de médico cardiologista. Cada UBS tem população adscrita entre 3.000 a 3.970 pessoas. Atenção secundária: 01 equipe NASF-AB vinculada às 06 ESF, composta por quatro profissionais: psicólogo, nutricionista, fisioterapeuta e assistente social; 01 CAPS tipo I, que atende álcool, drogas, doença mental e transtorno mental em todas as faixas etárias; 01 Clínica da Mulher e da Criança à qual estão vinculadas 3000. O município possui equipe de vigilância epidemiológica, vigilância sanitária, laboratório. Atenção terciária: 01 Hospital que em parte é suprido pelo Estado e em parte pelo município, há médicos plantonistas, que atendem emergências, não há maternidade.

O cadastro de usuários com queixas de sofrimento e transtornos mentais passou a ser gerenciado a partir de 2017. A classificação e estratificação de risco da condição de saúde mental não foi contemplada nesse primeiro momento, apenas o cadastro da população usuária de CAPS e psicotrópicos. Considera-se que muitos dados estejam em duplicidade visto 
que os usuários que necessitam de medicação controlada (psicotrópicos) são atendidos tanto no CAPS quanto nas UBS. Em 2016 o CAPS contava com mais de 600 prontuários e foram registrados dois óbitos ocasionados por transtornos mentais e comportamentais.

Os casos de pacientes em surto são encaminhados para o Hospital onde são medicados e permanecem internados até que se efetive a transferência. Todos os internamentos e/ou tratamentos de longo prazo que necessitem de hospitais ou clínicas especializadas são realizados fora do município.

\section{OBJETIVOS}

\section{OBJETIVO GERAL}

Promover a adequação dos trabalhos característicos à equipe NASF-AB, particularmente à área de saúde mental.

\section{OBJETIVOS ESPECIFICOS}

1. Identificar as possibilidades de ações em saúde mental no processo de trabalho do NASF-AB.

2. Desenvolver apoio matricial para as equipes de atenção primária em saúde:

3. Sistematizar a atenção em saúde mental utilizando instrumento oficial de estratificação para estabelecer um fluxograma de atendimento.

\section{REVISÃO DE LITERATURA}

A política higienista hegemônica até a
Reforma Psiquiátrica em 2001 privava de direitos os indivíduos que julgava loucos, excluindo-os do convívio social ${ }^{8}$. A "libertação" dos doentes mentais foi possivel a partir do fechamento dos manicômios a partir de 2001. O retorno à sociedade, à convivência familiar e social, trouxe a necessidade de adequações dos serviços de saúde pública. Nos anos que se seguiram, foram implementados Centros de Apoio Psicossocial - CAPS em vários municípios do País e consolidaram-se como dispositivos estratégicos para a superação do modelo asilar no contexto da reforma psiquiátrica, e para a criação de um novo lugar social para as pessoas com sofrimento, decorrentes de transtornos mentais, incluindo aquelas com necessidades relacionadas ao uso de álcool e de outras drogas?. A fim de atender as novas demandas os pontos de atenção não se limitaram aos CAPS, mas a um conjunto de ações abrangidas pela rede de atenção psicossocial (RAPS), instituída².

As UBS constituem-se na porta de entrada para os serviços públicos de saúde. Devido à alta demanda, as equipes da atenção básica necessitavam de suporte, assim o NASF surge em 2008 como apoio às equipes de ESF, propiciando à população alternativas de atendimento humanitárias, igualitárias, preventivas, com a intenção de aumentar a integralidade do cuidado, ampliar os núcleos de conhecimento em saúde e aumentar a resolubilidade das equipes de Atenção Básica $(A B)^{10,11,12}$.

Pode-se dizer atualmente que a beleza do NASF-AB é sua abrangência, pois tem a possibilidade de atuar em todo o território adscrito das ESF às quais está ligado, mas também em outras políticas públicas desse território, como a de assistência social, em parceria com Centros de Referência de Assistência Social 
(CRAS), Centro de Referência Especializado de Assistência Social (CREAS), educação, onde possui a faculdade para desenvolver diversas atividades, junto aos professores, pais e alunos, além de poder inserir-se na comunidade em grupos previamente estabelecidos em igrejas, associações de bairros, centros de convivência e organizações não governamentais (ONG).

O matriciamento ou apoio matricial pode ser realizado conjuntamente por mais de um profissional do NASF-AB, quando requer apoio de uma equipe transdisciplinar ou mais especificamente, como aqui procuramos enfocar, no que se refere à saúde mental; a proposta é sempre de integração da equipe, dos usuários, do território, considerando-se o princípio da horizontalidade, sem rivalidades ou grupos específicos de profissionais que não interagem, buscando ampliar conhecimentos e campo de atuação, na prática significa dizer que especialidades se intercalam pelo bom funcionamento do trabalho ${ }^{13}$.

\section{PROPOSTA METODOLÓGICA}

A proposta consiste em definir a atuação do NASF-AB, especialmente para a atenção à saúde mental, sensibilizar a equipe de APS para o trabalho e implementar fluxo de atendimento em saúde mental, para tanto utilizar-se-á de instrumentos a serem desenvolvidos como elaboração de uma agenda de carga horária para a psicologia, fluxograma de atendimento em saúde mental e apoio matricial à APS. Para o desenvolvimento das ações será utilizada a metodologia $\left.5 \mathrm{~W} 2 \mathrm{H}^{(14,15}\right)$.

$\mathrm{O}$ método $5 \mathrm{~W} 2 \mathrm{H}$ é um tipo de checklist utilizado para garantir que a operação seja conduzida sem nenhuma dúvida por parte das chefias e subordinados. Os $5 \mathrm{~W}$ correspondem às seguintes palavras do inglês: What (o que); Who (quem); Where (onde); When (quando) e Why (por que). Os $2 \mathrm{H}$ são: How (como) e How Much (quanto custa) $)^{14}$. 
PROPOSTA DE AÇÕES

QUADRO 1 PROPOSTA DE AÇÃO 1 DO OBJETIVO 1

\begin{tabular}{|c|c|}
\hline Objetivo Geral & $\begin{array}{l}\text { Promover a adequação dos trabalhos característicos à equipe NASF-AB, } \\
\text { particularmente à área de saúde mental. }\end{array}$ \\
\hline Objetivo Especifico 1 & $\begin{array}{l}\text { Identificar as possibilidades de ações em saúde mental no processo de } \\
\text { trabalho da psicologia no NASF-AB }\end{array}$ \\
\hline 0 que fazer? & $\begin{array}{l}\text { Análise da lista de espera dos encaminhamentos para a psicologia do Nasf- } \\
\text { AB realizada através do contato com os pacientes. }\end{array}$ \\
\hline Por que fazer? & $\begin{array}{l}\text { A análise da fila de espera possibilitará identificar e, possivelmente classificar, } \\
\text { pacientes encaminhados para atendimento com o profissional de psicologia } \\
\text { do Nasf-AB, de acordo com a causa e/ou razão do referenciamento. } \\
\text { A identificação dos motivos dos referenciamentos à psicologia do NASF-AB } \\
\text { traz à baila a possibilidade da criação de grupos de atendimento/ trabalho } \\
\text { em psicologia, terapêuticos com demandas semelhantes e/ou para atender a } \\
\text { qualquer outra necessidade identificada durante a análise da lista de espera. }\end{array}$ \\
\hline Onde fazer? & UBS, sala de atendimentos \\
\hline Quando fazer? & De outubro a dezembro de 2017 \\
\hline Quem fará? & $\begin{array}{l}\text { Profissional de psicologia do NASF-AB } \\
\text { Equipe APS: atendentes acolhimento/recepção }\end{array}$ \\
\hline Como será feito? & $\begin{array}{l}\text { Efetuar-se-ão até três ligações telefônicas a todas as pessoas que constam } \\
\text { na lista de espera; as ligações terão por finalidade verificar o real interesse } \\
\text { pelo atendimento, a disponibilidade de tempo da pessoa, a necessidade e/ou } \\
\text { urgência do atendimento e, de posse desses dados, marcar-se-á o atendi- } \\
\text { mento conforme disponibilidade de agenda do profissional; proceder-se-á } \\
\text { assim até a finalização da lista. } \\
\text { Para a realização da análise dos encaminhamentos utilizar-se-á da escuta } \\
\text { qualificada aplicada especificamente à psicologia, ou seja, os usuários serão } \\
\text { ouvidos, num primeiro momento, através do contato telefônico proposto e, } \\
\text { depois, se for o caso, pessoalmente. A quantificação dos motivos dos en- } \\
\text { caminhamentos, de acordo com a classificação em que poderiam enquadrar- } \\
\text { se (depressão, por exemplo) realizar-se-á posteriormente. }\end{array}$ \\
\hline Quanto custará? & $\begin{array}{l}\text { Custo de ligações de aparelho telefônico fixo disponível na unidade de } \\
\text { saúde para telefones de linhas fixas ou móveis. } \\
\text { Sem custos para a análise dos encaminhamentos, que dispenderá apenas de } \\
\text { horário livre do profissional de psicologia. }\end{array}$ \\
\hline
\end{tabular}

FONTE: 0 autor (2018) 
QUADRO 2 PROPOSTA DE AÇÃO 2 DO OBJETIVO 1

\begin{tabular}{|c|c|}
\hline Objetivo Geral & $\begin{array}{l}\text { Promover a adequação dos trabalhos característicos à equipe NASF-AB, } \\
\text { particularmente à área de saúde mental. }\end{array}$ \\
\hline Objetivo Especifico 1 & $\begin{array}{l}\text { Identificar as possibilidades de ações em saúde mental no processo } \\
\text { de trabalho da psicologia no NASF-AB }\end{array}$ \\
\hline \multirow{2}{*}{0 que fazer? } & $\begin{array}{l}\text { Reorganizar agenda da área da psicologia do NASF-AB a partir das } \\
\text { necessidades identificadas }\end{array}$ \\
\hline & $\begin{array}{l}\text { Disponibilizar horários na agenda do profissional de psicologia do NASF-AB para } \\
\text { atender a demanda de trabalho deste núcleo de saber }\end{array}$ \\
\hline Por que fazer? & $\begin{array}{l}\text { O profissional de psicologia do NASF-AB não estava inserido em todas as } \\
\text { modalidades de atenção habilitadas a esse núcleo de saber e, para sua inserção, } \\
\text { a partir da identificação das necessidades, faz-se necessária a reorganização } \\
\text { da agenda de trabalho, que deverá ser mais abrangente, não apenas voltada ao } \\
\text { atendimento clínico, como acontecia anteriormente. }\end{array}$ \\
\hline Onde fazer? & UBS, sala de atendimentos \\
\hline Quando fazer? & Novembro de 2018 \\
\hline Quem fará? & Equipes NASF-AB e APS \\
\hline \multirow{7}{*}{ Como será feito? } & $\begin{array}{l}\text { Tomar-se-á como base para preparação da agenda orientações apresentadas } \\
\text { nos cadernos nº } 39 \text { e } 34 \text { do Ministério da Saúde }{ }^{11,12} \text {, ficando assim dividida, } \\
\text { considerando-se as } 40 \text { horas semanais de trabalho do profissional de psicologia do } \\
\text { NASF-AB: }\end{array}$ \\
\hline & $\begin{array}{l}\text { a) Atendimento quinzenal nos dois distritos administrativos, perfazendo um } \\
\text { total de } 08 \text { horas semanais, correspondentes a } 20 \% \text { da carga horária semanal } \\
\text { total; }\end{array}$ \\
\hline & $\begin{array}{l}\text { b) Atendimento semanal na UBS 1, perfazendo um total de } 04 \text { horas semanais, } \\
\text { correspondentes a } 10 \% \text { da carga horária semanal total; }\end{array}$ \\
\hline & $\begin{array}{l}\text { c) Atendimento semanal na UBS 2, perfazendo um total de } 08 \text { horas semanais, } \\
\text { correspondentes a } 20 \% \text { da carga horária semanal total; }\end{array}$ \\
\hline & $\begin{array}{l}\text { d) Atendimento semanal na UBS } 2 \text { para triagem agendada, perfazendo um total } \\
\text { de } 04 \text { horas semanais, correspondentes a } 10 \% \text { da carga horária semanal total; }\end{array}$ \\
\hline & $\begin{array}{l}\text { e) Destinação de } 08 \text { horas semanais, divididas ao que corresponde a 05\% da } \\
\text { carga horária semanal à realização de diferentes atividades relativas ao Nasf- } \\
\text { AB, tais como, grupos terapêuticos e/ou outros, visitas domiciliares conjuntas, } \\
\text { matriciamento, atividades administrativas, salientando-se que esse total } \\
\text { poderá ser redistribuído de acordo com a necessidade apresentada. }\end{array}$ \\
\hline & $\begin{array}{l}\text { f) Destinação de } 08 \text { horas semanais, divididas de acordo com a necessidade, } \\
\text { para participação em atividades realizadas mensalmente, tais como reunião de } \\
\text { equipe, reunião de matriciamento, reunião Nasf-AB, participação em conselhos } \\
\text { municipais, participação em grupos das UBS. }\end{array}$ \\
\hline Quanto custará? & $\begin{array}{l}\text { Os custos referem-se a deslocamentos que serão realizados com carro oficial } \\
\text { disponível, custo absorvido pela SMS nas atividades diárias e à alimentação } \\
\text { do profissional de psicologia do NASF-AB quando em atividade nos distritos } \\
\text { administrativos, igualmente suprido pela Secretaria Municipal de Saúde com } \\
\text { o fornecimento de autorização para alimentação nos estabelecimentos locais } \\
\text { cadastrados junto ao município. }\end{array}$ \\
\hline
\end{tabular}

FONTE: 0 autor (2018) 
QUADRO 3 PROPOSTA DE AÇÃO 1 DO OBJETIVO 2

\begin{tabular}{|c|c|}
\hline Objetivo Geral & $\begin{array}{l}\text { Promover a adequação dos trabalhos característicos à equipe NASF-AB } \\
\text { particularmente à área de saúde mental }\end{array}$ \\
\hline Objetivo Especifico 2 & Desenvolver apoio matricial para as equipes de APS. \\
\hline Ação 1 & Participação em grupos da APS \\
\hline 0 que fazer? & $\begin{array}{l}\text { Inserir o profissional de psicologia do NASF-AB em dois dos grupos de } \\
\text { apoio estabelecidos na unidade de saúde, o grupo denominado "Chá de } \\
\text { Bebê" com atividades educativas para as gestantes adscritas à UBS } 1 \\
\text { e } 2 \text { e, "Grupo de Apoio à Perda de Peso", que trabalha com reeducação } \\
\text { alimentar para usuários das UBS. }\end{array}$ \\
\hline Por que fazer? & $\begin{array}{l}\text { A participação do profissional de psicologia do NASF-AB nos grupos } \\
\text { faz parte das possibilidades de atuação deste, da adequação de } \\
\text { trabalho proposta, e possibilita amplitude do trabalho relacionado a } \\
\text { temas abordados com frequência na clínica como ansiedade, depressão, } \\
\text { insegurança, questões relativas à autoestima, que apresentam-se } \\
\text { com regularidade nesse recorte significativo representado pelos dois } \\
\text { grupos, evitando possíveis atendimentos individuais, como decorrência, } \\
\text { colaborando para a eliminação da fila de espera, conforme descrito na } \\
\text { ação } 1 \text { do objetivo } 1 .\end{array}$ \\
\hline Onde fazer? & Salão do idoso \\
\hline Quando fazer? & $\begin{array}{l}\text { Grupo "Chá de Bebê", toda primeira segunda-feira de cada mês, das } \\
14 \text { h às } 16 \text { h, a partir do mês de outubro de } 2017 . \\
\text { "Grupo de Apoio à Perda de Peso", toda segunda sexta-feira do mês, } \\
\text { das } 15 \text { h às 17h, a partir de outubro de } 2017 .\end{array}$ \\
\hline Quem fará? & $\begin{array}{l}\text { Profissional de medicina clínica da ESF } 1 \text { da UBS } \\
\text { Profissional de nutrição doNASF-AB } \\
\text { Profissional de Psicologia do NASF-AB }\end{array}$ \\
\hline Como será feito? & $\begin{array}{l}\text { O profissional de psicologia do NASF-AB disponibilizará 15\% (quinze } \\
\text { por cento) de sua carga horária semanal (06h) para a participação nos } \\
\text { grupos de apoio citados; a atuação será realizada na modalidade "roda } \\
\text { de conversa". }\end{array}$ \\
\hline Quanto custará? & $\begin{array}{l}\text { Deslocamento para o salão do idoso realizado com carro oficial } \\
\text { disponível, custo absorvido pela SMS nas atividades diárias. }\end{array}$ \\
\hline
\end{tabular}

FONTE: 0 autor (2018) 
QUADRO 4 PROPOSTA DE AÇÃO 2 DO OBJETIVO 2

\begin{tabular}{|c|c|}
\hline Objetivo Geral & $\begin{array}{l}\text { Promover a adequação dos trabalhos característicos à equipe NASF-AB. } \\
\text { particularmente à área de saúde menta. }\end{array}$ \\
\hline Objetivo Especifico 2 & Desenvolver apoio matricial para as equipes de APS. \\
\hline Ação 2 & Organização de grupos \\
\hline 0 que fazer? & $\begin{array}{l}\text { Estabelecer e/ou criar, grupos de atendimento em psicologia, de } \\
\text { acordo com a necessidade apresentada. }\end{array}$ \\
\hline Por que fazer? & $\begin{array}{l}\text { Um grupo específico de atendimento em psicologia faz parte das } \\
\text { possibilidades de atuação do profissional de psicologia do Nasf-AB, } \\
\text { bem como da adequação de trabalho proposta, e possibilita ainda } \\
\text { maior alcance da atuação do psicólogo à comunidade. }\end{array}$ \\
\hline Onde fazer? & Salão do idoso \\
\hline Quando fazer? & Janeiro de 2019, ou quando se apresentar a necessidade. \\
\hline Quem fará? & Profissional de psicologia do NASF-AB. \\
\hline Como será feito? & $\begin{array}{l}\text { A partir da identificação da necessidade, com um mínimo de seis } \\
\text { pessoas participantes, eleger-se-á data semanal e horário fixo para } \\
\text { início das atividades, no primeiro encontro serão discutidos os critérios } \\
\text { de funcionamento do grupo, tais como frequência, sigilo, entre outros. }\end{array}$ \\
\hline Quanto custará? & $\begin{array}{l}\text { Deslocamento para o salão do idoso realizado com carro oficial } \\
\text { disponível, custo absorvido pela SMS nas atividades diárias. }\end{array}$ \\
\hline
\end{tabular}

FONTE: O autor (2018)

QUADRO 5 PROPOSTA DE AÇÃO 3 DO OBJETIVO 2

\begin{tabular}{|c|l|}
\hline \multicolumn{1}{|c|}{ Objetivo Geral } & $\begin{array}{l}\text { Promover a adequação dos trabalhos característicos à equipe NASF-AB, } \\
\text { particularmente à área de saúde mental }\end{array}$ \\
\hline Objetivo Especifico 2 & Desenvolver apoio matricial para as equipes de APS. \\
\hline 0 que fazer? & $\begin{array}{l}\text { Utilizar as ferramentas para apoio matricial juntos às ESF. } \\
\text { Estabelecer, na prática das ESF atendidas pelo profissional de psicologia, os } \\
\text { instrumentos matriciais do NASF-AB, a saber, Projeto Terapêutico Singular } \\
\text { (PTS), Interconsulta, Consulta conjunta, Visita domiciliar conjunta, Contato à } \\
\text { distância, Genograma, Ecomapa. }\end{array}$ \\
\hline
\end{tabular}


QUADRO 5 PROPOSTA DE AÇÃO 3 DO OBJETIVO 2

\begin{tabular}{|c|c|}
\hline Por que fazer? & $\begin{array}{l}\text { A fim de adequar o profissional de psicologia do NASF-AB ao trabalho } \\
\text { característico deste núcleo de saber, possibilitando extensão do rol de atividades } \\
\text { anteriormente restrito a atendimento ambulatorial bem como ampliando a Rede } \\
\text { de Atenção Psicossocial (RAPS). }\end{array}$ \\
\hline Onde fazer? & Nas Unidades de Saúde às quais o NASF-AB está inserido. \\
\hline Quando fazer? & $\begin{array}{l}\text { PTS: Janeiro de 2019, quando se apresentar necessário. Interconsulta: Outubro } \\
\text { de } 2017 \text { quando se apresentar necessário. } \\
\text { Consulta conjunta: Maio de } 2019 . \\
\text { Visita domiciliar conjunta: Julho de 2019, quando necessário. } \\
\text { Contato à distância: Janeiro de } 2019 \\
\text { Genograma: Agosto e Setembro de } 2019 \\
\text { Ecomapa: Outubro e Novembro de } 2019\end{array}$ \\
\hline Quem fará? & $\begin{array}{l}\text { PTS: Equipes NASF-AB, APS. Interconsulta: Equipes NASF-AB, APS. } \\
\text { Consulta conjunta: Profissional de psicologia do NASF-AB, profissionais de } \\
\text { medicina nas especialidades clínica, psiquiatria, neurologia. } \\
\text { Visita domiciliar conjunta: Profissional de psicologia do NASF-AB, ACS, } \\
\text { outras especialidades profissionais como médicos, enfermeiros, nutricionistas, } \\
\text { assistentes sociais, de acordo com a necessidade apresentada. } \\
\text { Contato à distância: NASF-AB. } \\
\text { Genograma: NASF-AB. } \\
\text { Ecomapa: Equipes NASF-AB, APS. }\end{array}$ \\
\hline Como será feito? & $\begin{array}{l}\text { PTS: Elaborado em reunião com a participação das equipes NASF-AB, APS, } \\
\text { CAPS, gestores, usuário. } \\
\text { Interconsulta: Interação, troca de experiências entre as equipes NASF-AB., APS, } \\
\text { CAPS, especialidades médicas, quando necessário, através de contato pessoal } \\
\text { nas UBS, reuniões de equipe da APS, do NASF-AB, ou à distância via telefone, } \\
\text { e-mail, whatsapp. } \\
\text { Consulta conjunta: Realizada para atender casos específicos, previamente } \\
\text { agendado ou, em caráter emergencial, quando necessário, contando com a } \\
\text { participação do profissional de psicologia do NASF e especialidades profissionais } \\
\text { tais como médico clínico, psiquiatra, neurologista. } \\
\text { Visita domiciliar conjunta: De acordo com a necessidade relatada pelo ACS } \\
\text { responsável pela área, diretamente ou em reunião de equipe da APS, realizada } \\
\text { pelo profissional de psicologia do NASF-AB e ACS. } \\
\text { Contato à distância: Realizado via telefone fixo, móvel, mensagens de e- mail, } \\
\text { whatsapp, a qualquer tempo, em horário comercial. } \\
\text { Genograma: matriciamento do NASF à APS* Ecomapa: matriciamento do NASF } \\
\text { à APS* } \\
\text { *Serão discriminados nas ações do Objetivo Específico } 2\end{array}$ \\
\hline Quanto custará? & $\begin{array}{l}\text { Os recursos financeiros previstos são considerados de baixo impacto nas } \\
\text { despesas, pois estão disponíveis em todas as UBS, podendo ser } \\
\text { disponibilizados pelo gestor da Secretaria de Saúde sem necessidade de } \\
\text { alteração no orçamento. }\end{array}$ \\
\hline
\end{tabular}

FONTE: 0 autor (2018) 
QUADRO 6 PROPOSTA DE AÇÃO 4 DO OBJETIVO 2

\begin{tabular}{|c|c|}
\hline Objetivo Geral & $\begin{array}{l}\text { Promover a adequação dos trabalhos característicos à equipe NASF-AB, } \\
\text { particularmente à área de saúde mental }\end{array}$ \\
\hline Objetivo Específico 2 & Desenvolver apoio matricial para as equipes de APS. \\
\hline 0 que fazer? & $\begin{array}{l}\text { Capacitar as equipes de APS para identificar sofrimento mental, bem } \\
\text { como realizar abordagens como acolhimento, escuta ativa de maneira mais } \\
\text { adequada e efetiva em relação a usuários de saúde mental. }\end{array}$ \\
\hline Por que fazer? & $\begin{array}{l}\text { Facilitar a identificação, por parte da equipe da APS, de casos relacionados } \\
\text { à saúde/sofrimento mental, bem como proporcionar a abordagem } \\
\text { adequada, livre de temores e estigmas. }\end{array}$ \\
\hline Onde fazer? & Sala de reuniões das UBS. \\
\hline Quando fazer? & Junho de 2019 e Dezembro de 2019 \\
\hline Quem fará? & $\begin{array}{l}\text { Equipe NASF: profissional de psicologia } \\
\text { Equipe APS: profissionais medicina, enfermagem }\end{array}$ \\
\hline Como será feito? & $\begin{array}{l}\text { Apresentar-se-á conteúdo escrito sobre como pode-se identificar pessoas } \\
\text { portadoras de sofrimento e/ou doença mental, quais as abordagens } \\
\text { adequadas, exercício com apresentação de caso prático, esclarecimento de } \\
\text { dúvidas; realizar-se-á durante as reuniões de equipe da APS. }\end{array}$ \\
\hline Quanto custará? & $\begin{array}{l}\text { Os recursos financeiros previstos são considerados de baixo impacto } \\
\text { nas despesas, pois estão disponíveis em todas as UBS, podendo ser } \\
\text { disponibilizados pelo gestor da Secretaria de Saúde sem necessidade de } \\
\text { alteração no orçamento. }\end{array}$ \\
\hline
\end{tabular}

FONTE: O autor (2018) 
QUADRO 7 PROPOSTA DE AÇÃO 5 DO OBJETIVO 2

\begin{tabular}{|c|c|}
\hline Objetivo Geral & $\begin{array}{l}\text { Promover a adequação dos trabalhos característicos à equipe NASF-AB, } \\
\text { particularmente à área de saúde mental }\end{array}$ \\
\hline Objetivo Especifico 2 & Desenvolver apoio matricial para as equipes de APS. \\
\hline 0 que fazer? & $\begin{array}{l}\text { a) Capacitar os profissionais de nível superior que atuam na modalidade } \\
\text { ambulatorial para realizar o Genograma. } \\
\text { b) Capacitar os ACS para realizar o Ecomapa. }\end{array}$ \\
\hline Por que fazer? & $\begin{array}{l}\text { Ampliar o conhecimento da realidade do usuário do serviço de saúde, suas } \\
\text { interações familiares, sociais, laborais, com a finalidade de proporcionar } \\
\text { cuidado mais adequado, inclusive em termos preventivos. }\end{array}$ \\
\hline Onde fazer? & Sala de reuniões das UBS. \\
\hline Quando fazer? & $\begin{array}{l}\text { Genograma: Agosto e Setembro de } 2019 \\
\text { Ecomapa: Outubro e Novembro de } 2019\end{array}$ \\
\hline Quem fará? & Equipe NASF: profissional de psicologia \\
\hline Como será feito? & $\begin{array}{l}\text { Genograma: Apresentação de conteúdo teórico explicativo ilustrado sobre } \\
\text { o tema, com apoio de material trabalhado no curso de especialização em } \\
\text { saúde mental na atenção primária, bem como literatura oficial do MS, } \\
\text { exercícios práticos, esclarecimento de dúvidas, seguimento com supervisão, } \\
\text { se necessário. } \\
\text { Ecomapa: Apresentação de conteúdo teórico explicativo ilustrado sobre } \\
\text { otema, apoio de literatura oficial do MS, exercícios práticos, esclarecimentos } \\
\text { de dúvidas, seguimento com supervisão, se necessário. }\end{array}$ \\
\hline Quanto custará? & $\begin{array}{l}\text { Os recursos financeiros previstos são considerados de baixo impacto } \\
\text { nas despesas, pois estão disponíveis em todas as UBS, podendo ser } \\
\text { disponibilizados pelo gestor da Secretaria de Saúde sem necessidade } \\
\text { dealteração no orçamento. }\end{array}$ \\
\hline
\end{tabular}

FONTE: O autor (2018) 
QUADRO 8 PROPOSTA DE AÇÃO 1 DO OBJETIVO 3

\begin{tabular}{|c|c|}
\hline Objetivo Geral & $\begin{array}{l}\text { Promover a adequação dos trabalhos característicos à equipe NASF-AB, } \\
\text { particularmente à área de saúde mental }\end{array}$ \\
\hline Objetivo Especifico 3 & $\begin{array}{l}\text { Sistematizar a atenção em saúde mental utilizando instrumento oficial de } \\
\text { estratificação para estabelecer fluxograma de atendimento. }\end{array}$ \\
\hline 0 que fazer? & $\begin{array}{l}\text { Capacitar profissionais do quadro efetivo, com nível superior de } \\
\text { escolaridade, atuantes na APS e CAPS para utilizar o instrumento } \\
\text { Estratificação de Risco em Saúde Mental. }{ }^{16}\end{array}$ \\
\hline Por que fazer? & $\begin{array}{l}\text { O instrumento estratificação de Risco em Saúde Mental16 possibilitará } \\
\text { quantificar os usuários dos serviços de saúde mental, e definirá, no } \\
\text { momento, a classificação do sofrimento mental, possibilitando inserção } \\
\text { no serviço mais adequado à necessidade atual, evitando retrabalho, } \\
\text { atendimentos incompletos e/ou inadequados; com os dados obtidos é } \\
\text { possível elaborar-se fluxograma de atendimento em saúde mental. }\end{array}$ \\
\hline Onde fazer? & Nas salas de atendimento das UBS da sede, do interior, do CAPS. \\
\hline Quando fazer? & Fevereiro de 2019 \\
\hline Quem fará? & $\begin{array}{l}\text { Profissional médico psiquiatra e/ou médico clínico geral com conhecimento } \\
\text { acerca de saúde mental. }\end{array}$ \\
\hline Como será feito? & $\begin{array}{l}\text { Encontros presenciais agendados antecipadamente, onde utilizar-se-á o } \\
\text { instrumento de estratificação de risco em saúde mental disponível nas } \\
\text { Oficinas de Atenção Primária à Saúde de Qualidade em todo o Paraná } \\
\text { (APSUS), oficina 8, saúde mental'16. }\end{array}$ \\
\hline Quanto custará? & $\begin{array}{l}\text { Os recursos financeiros previstos são considerados de baixo impacto } \\
\text { nas despesas, pois estão disponíveis em todas as UBS podendo ser } \\
\text { disponibilizados pelo gestor da Secretaria de Saúde sem necessidade de } \\
\text { alteração no orçamento geral. }\end{array}$ \\
\hline
\end{tabular}

FONTE: O autor (2018) 
QUADRO 9 PROPOSTA DE AÇÃO 2 DO OBJETIVO 3

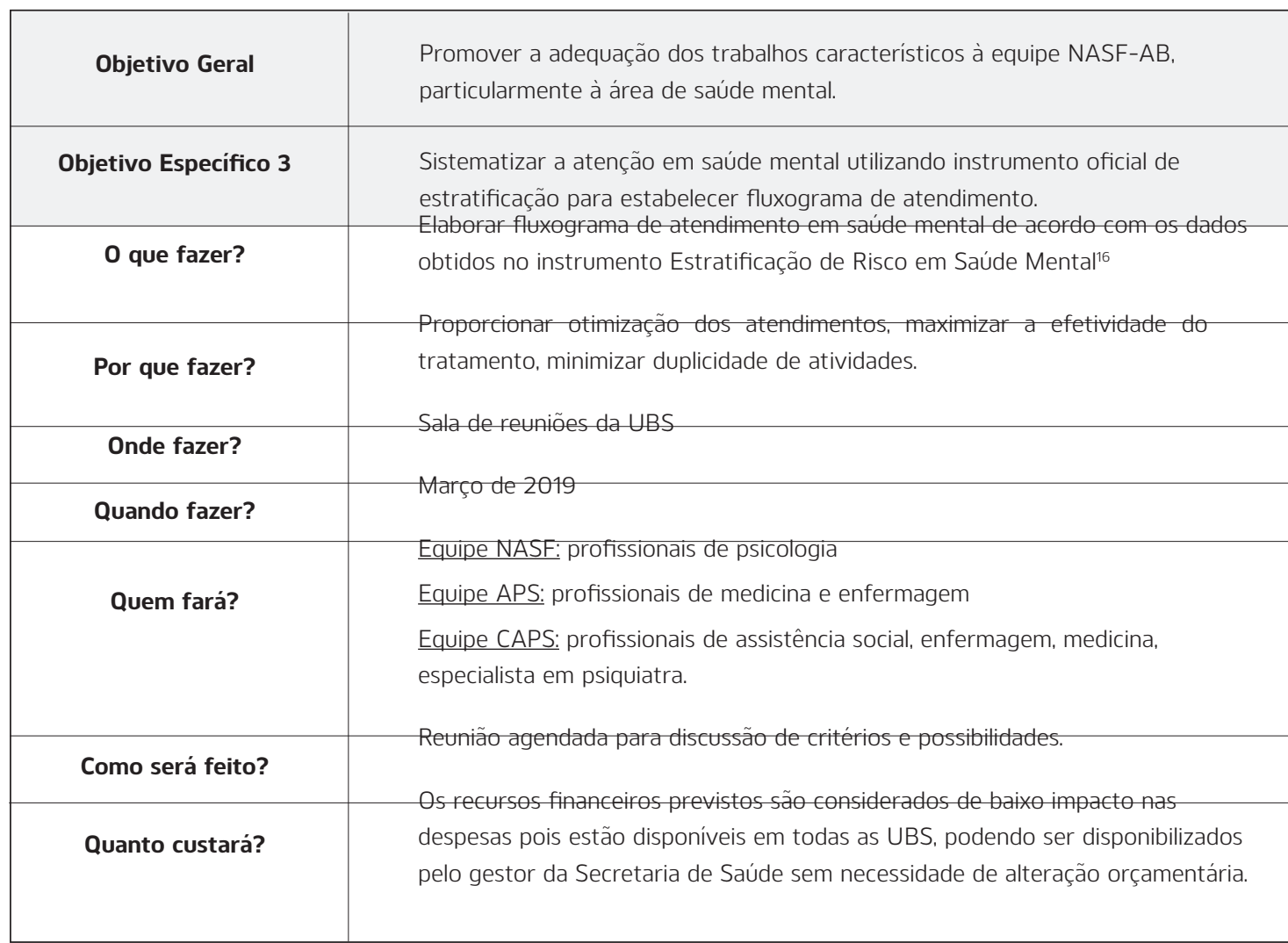

FONTE: O autor (2018)

QUADRO 10 PROPOSTA DE AÇÃO 3 DO OBJETIVO 3

\begin{tabular}{|c|c|}
\hline Objetivo Geral & $\begin{array}{l}\text { Promover a adequação dos trabalhos característicos à equipe NASF-AB, } \\
\text { particularmente à área de saúde mental }\end{array}$ \\
\hline Objetivo Especifico 3 & $\begin{array}{l}\text { Sistematizar a atenção em saúde mental utilizando instrumento oficial de } \\
\text { estratificação para estabelecer fluxograma de atendimento. }\end{array}$ \\
\hline 0 que fazer? & Elaborar protocolo de atendimento em saúde mental nas UBS \\
\hline Por que fazer? & Sistematizar critérios para atendimento ambulatorial em psicologia \\
\hline Onde fazer? & Sala de atendimento da psicologia na UBS \\
\hline Quando fazer? & Abril de 2019 \\
\hline Quem fará? & Profissional de psicologia do NASF, Gestor da UBS \\
\hline Como será feito? & Reunião agendada para estabelecimento dos critérios \\
\hline Quanto custará? & $\begin{array}{l}\text { Os recursos financeiros previstos são considerados de baixo impacto nas } \\
\text { despesas pois estão disponíveis em todas as UBS, podendo ser disponibilizados } \\
\text { pelo gestor da Secretaria de Saúde sem necessidade de alteração no } \\
\text { orçamento geral. }\end{array}$ \\
\hline
\end{tabular}

FONTE: O autor (2018) 


\section{MONITORAMENTO E AVALIAÇÃO}

Definir indicadores para monitoramento e avaliação é um ponto fundamental para a institucionalização deste projeto. Para tanto será importante registrar todas as evidências de cumprimento e realização dos objetivos e ações propostos por meio de: listas de presença assinadas pelos usuários nos grupos realizados, atas de reunião das equipes, periodicidade das ações, registro de discussões apontando pontos que favorecem e dificultam a continuidade do projeto e outros registros que podem compor um "diário de bordo" do Projeto. Espera-se ter um registro descritivo e reflexivo sobre o andamento do projeto de modo que a partir dele possam ser extraídos melhores indicadores para monitoramento e avaliação.

\section{RESULTADOS PARCIAIS}

No que se refere à primeira ação do objetivo 1, a análise da lista de espera realizou-se no período previsto, com excelente efetividade, a lista de espera foi eliminada e a triagem semanal mostrou-se de grande valia, as demandas dos usuários são acolhidas e as ações necessárias são propostas imediatamente.

Quanto à primeira ação do objetivo 2 . participação em grupos da APS, o trabalho foi iniciado, embora com menor efetividade, devido à incompatibilidade de agenda dos profissionais, perdurou por alguns meses, depois foi descontinuado, com proposta de retomada para o ano de 2019.

No que se relaciona à ação 3 do segundo objetivo, a interconsulta realiza-se de acordo com a necessidade, de maneira efetiva e eficaz.
Os demais objetivos não apresentam resultados parciais por tratar-se de propostas ainda não estabelecidas.

\section{CONSIDERAÇÕES FINAIS}

O século XXI está chegando na sua segunda década, avanços tecnológicos se fazem presentes em nossas vidas a todo instante, a saúde mental ganha seu espaço de discussão no dia a dia das instituições de saúde, na sociedade. nas escolas, a inserção se faz presente, embora ainda trazendo consigo alguns estigmas, por isso trabalhos desenvolvidos por núcleos de saber tais como se apresentam os NASF-AB, com sua capacidade de transitar entre o território, os usuários, a equipe das UBS, as demais políticas sociais, os tornam de grande valia para a saúde, em especial a saúde mental.

Diante de toda essa importância é que se faz tão urgente a ampliação do rol de atividades do NASF-AB em saúde mental. Considerando que todos os recursos estruturais, físicos e humanos estão disponíveis, o investimento necessário é em tecnologias relacionais, interpessoais, para articulação de processos de trabalho. Este projeto tem foco na saúde mental e o profissional psicólogo foi considerado um articulador para ampliar o acolhimento e a atenção nas equipes das UBS, no entanto, a atenção à saúde mental não é de competência exclusiva do núcleo de conhecimento da psicologia. Espera-se ao longo deste projeto, que todos os profissionais e a comunidade se sensibilizem para o acolhimento de pessoas em sofrimento mental. Entende-se que não se trata 
apenas de atenção especializada, mas muito de apoio social, familiar e multiprofissional.

\section{Participar do curso de especialização} em saúde mental na atenção básica à saúde e desenvolver esse PA mostrou ser viável a efetivação destas possibilidades, e a apresentação física das propostas representadas nas páginas desse trabalho permite sua visualização e total aplicabilidade, sabendo, inclusive, que o aqui representado é uma pequena parcela de tudo o que pode ser realizado.

\section{REFERÊNCIAS}

1. BRASIL. LEI No 10.216, DE 6 DE ABRIL DE 2001. Dispõe sobre a proteção e os direitos das pessoas portadoras de transtornos mentais e redireciona o modelo assistencial em saúde mental.

2. BRASIL. Portaria $n^{\circ}$ 3.088, de 23 de dezembro de 2011. Institui a Rede de Atenção Psicossocial para pessoas com sofrimento ou transtorno mental e com necessidades decorrentes do uso de crack, álcool e outras drogas, no âmbito do Sistema Único de Saúde (SUS).

3. BRASIL. Portaria $n^{\circ} 154$, de 24 de janeiro de 2008. Cria os Núcleos de Apoio à Saúde da Família - NASF.

4. BRASIL. Ministério da Saúde. Secretaria de Atenção à Saúde PNAB: política nacional de atenção básica. Brasília: Ministério da Saúde, 2012. 114 p.

5. MINISTÉRIO DA SAÚDE. PORTARIA N 2.436, DE 21 DE SETEMBRO DE 2017. Aprova a Política Nacional de Atenção Básica PNAB: estabelecendo a revisão de diretrizes para a organização da Atenção Básica, no âmbito do Sistema Único de Saúde (SUS).

6. BRASIL. IBGE. Brasil. Estatística por cidade e estado: Tibagi. 2010. Brasil. Disponivel em: <www.ibge.gov.br>. Acesso em: 08 nov. 2017.

7. PARANÁ. IPARDES. Caderno Estatístico Município Tibagi. 2017 Disponivel em: <www.ipardes.gov.br>. Acesso em 08/11/2017.

8. AMARANTE, Paulo Duarte de Carvalho (Org.). Psiquiatria social e reforma psiquiátrica. Rio de Janeiro: Fiocruz, 1994. Cap. 3. p. 01-202.

9. BRASIL. MINISTÉRIO DA SAÚDE. Centros de atenção psicossocial como lugares da atenção psicossocial nos territórios: orientações para elaboração de projetos de construção, reforma e ampliação de CAPS e de UA. Brasília: Ministério da Saúde, 2015. $41 \mathrm{p}$.

10. BRASIL MINISTÉRIO DA SAÚDE Cadernos de atenção básica $n^{\circ}$ 27: diretrizes do NASF: núcleo de apoio à saúde da família. Brasília: Ministério da Saúde, 2010. 150 p.
11. BRASIL. MINISTÉRIO DA SAÚDE. Cadernos de atenção básica n 39: núcleo de apoio à saúde da família - volume I: ferramentas para a gestão e para o trabalho cotidiano. Brasília, 2014. 116 p.

12. BRASIL. MINISTÉRIO DA SAÚDE. Cadernos de atenção básica $n^{\circ}$ 34: saúde Mental. Brasília: Ministério da Saúde, 2013. 171 p.

13. Campos GWS, Domitti AC. Apoio matricial e equipe de referência: uma metodologia para gestão do trabalho interdisciplinar em saúde. Caderno de Saúde Pública, Rio de Janeiro, v. 2, n. 23, p.399407, fev. 2007.

14. Candeloro R (Brasil). Não tenha dúvidas: método 5W2H. 2008 Disponivel em: <www.administradores.com.br>. Acesso em: 13 set. 2018

15. Marques JR. O que é a metodologia 5W2H? 2016. Disponíve em: <www.jrmcoaching.com.br>. Acesso em: 19 set. 2018.

16. PARANÁ. Oficinas do APSUS: formação e qualificação do profissional em atenção primária à saúde: Oficina 8: Saúde Mental. Curitiba: Paraná, 2014. 42p. 